\title{
Looking Forward Approach for dynamic cooperative advertising game model ${ }^{*}$
}

\author{
L. Shi, O. L. Petrosian, A. V. Boiko
}

St. Petersburg State University, 7-9, Universitetskaya nab., St. Petersburg, 199034, Russian Federation

For citation: Shi L., Petrosian O. L., Boiko A. V. Looking Forward Approach for dynamic cooperative advertising game model. Vestnik of Saint Petersburg University. Applied Mathematics. Computer Science. Control Processes, 2019, vol. 15, iss. 2, pp. 221-234. https://doi.org/10.21638/11702/spbu10.2019.206

In this paper, we examine a dynamic cooperative advertising game model, where each firm market share depends on its own and its competitors' advertising decisions. More and more companies are willing to cooperate on the market in order to increase their market share and their joint profit as a result. They cooperate on advertising acting as one company and according to a characteristic function introduced in this work, their joint profit can be reallocated according to some cooperative solution. Looking Forward Approach is applied to the initial game in order to construct a model, where information about the process updates dynamically. Comparison between the solution of initial game model and game model with dynamic updating is illustrated using the numerical simulation.

Keywords: dynamic games, dynamic cooperative games, time consistency, looking forward approach.

1. Introduction. Advertising as a strategy for market competition has been studied in many marketing models and in this paper, we are concentrating on the dynamic advertising model. Here each firm's market share depends on its own and its competitors' current and past advertising expenditures. Competition between firms is formulated by the non-cooperative differential game as it was done in [1-6]. In this paper we consider an oligopoly advertising model of [5] and apply Looking Forward Approach (LFA) in order to model the behavior of firms in case of dynamic updating of information.

LFA is used for constructing game theoretical models and defining solutions for conflict controlled processes where information about the process updates dynamically. In works [7-14] are published most recent results on this topic. Existing dynamic games often rely on the assumption of time invariant game structures for derivation of equilibrium solutions. However, many events in the considerably far future are intrinsically unknown. It is supposed that players lack certain information about the motion equations and payoff functions on the whole time interval on which the game is played. At each time instant when information about the game structure updates, players receive updated information about the motion equations and payoff functions and adapt to the updates. This new approach for the analysis of dynamic games via information updating provides a more realistic and practical alternative to the study of dynamic games. There was also work [15] related to the game models with shifting planning horizon, where authors study dynamic game models for labor stimulation. It is important to notice that the overall study of games with dynamic updating is dedicated to the problem of construction of a general theory, in particular, for a class of cooperative dynamic or differential games with dynamic updating,

* Research was supported by a grant from the Russian Science Foundation (project N 18-71-00081).

(c) Санкт-Петербургский государственный университет, 2019 
where important question is how to construct cooperative solution and what properties of this solution are.

It's worth mentioning that LFA is similar in substance to the Model Predictive Control theory developed within the framework of numerical optimal control, for recent results in the field see [16-18]. But the main problem that is solved by the Model Predictive Control is the provision of movement along the target trajectory under the conditions of random perturbations and unknown motion equations, which leads system to the target trajectory. LFA on the other hand solves the problem of modeling players behavior when information about the process updates dynamically.

In section 2 the initial game model of oligopoly advertising is presented. In section 3 the corresponding game model with dynamic updating is studied and the solution is derived. In section 4 the numerical simulation is performed and the comparison between the solution of the initial game model and the game model with dynamic updating is presented.

2. Oligopoly advertising dynamic game model. We transform differential game model from [5] to the corresponding discrete time game using Finite Difference Method (FDM). Then the market share dynamics $x_{i}$ of firm $i$ for dynamic game model is

$$
\begin{gathered}
x_{i}^{\gamma+1}=h\left(\frac{n}{n-1} \rho_{i} u_{i}^{\gamma} \sqrt{1-x_{i}^{\gamma}}-\frac{1}{n-1} \sum_{j \in I} \rho_{j} u_{j}^{\gamma} \sqrt{1-x_{j}^{\gamma}}\right)-(h \delta-1) x_{i}^{\gamma}+h \delta \frac{1}{n} \\
x_{i}^{0}=z_{i}^{0} .
\end{gathered}
$$

In (1) $z_{i}^{0}$ is a positive constant. In order to apply FDM, we introduce the equally distributed grid points $\left(t_{\gamma}\right)_{\gamma=\overline{0, N}}$, where $t_{\gamma}=\gamma h, N$ is an integer and the spacing $h$ is given by $h=T / N$ and $x_{\gamma} \simeq x\left(t_{\gamma}\right)$ for all $\gamma=\overline{0, N}$. Therefore we suppose that the initial game is defined on the time interval with length $T$.

Payoff function of firm $i$ in dynamic game model has the form

$$
K_{i}^{0}\left(x^{0}, u\right)=\sum_{\gamma=0}^{N}\left[m_{i} x_{i}^{\gamma}-\left(u_{i}^{\gamma}\right)^{2}\right] .
$$

In expression (2) there is a logical consistency requirement that the market shares should satisfy:

$$
\sum_{i \in I} x_{i}^{\gamma}=1, x_{i}^{\gamma} \geqslant 0, i \in I, \quad \gamma=\overline{0, N}
$$

In table the list of parameters of the model is presented.

Table. List of variables and parameters

\begin{tabular}{|c|l|}
\hline Notation & Explanation \\
\hline$x_{i}^{\gamma} \in[0,1]$ & Market share of firm $i \in I=\{1, \ldots, n\}$ at stage $\gamma$ \\
$u_{i}^{\gamma} \geqslant 0$ & Advertising effort rate of firm $i$ at stage $\gamma$ \\
$\rho_{i}>0$ & Advertising effectiveness parameter of firm $i$ \\
$\delta>0$ & Churn parameter \\
$m_{i}>0$ & Industry sales multiplied by the per unit \\
& profit margin of firm $i$ \\
$C\left(u_{i}(t)\right)$ & Cost of advertising of firm $i$, presented as $\left(u_{i}(t)\right)^{2}$ \\
\hline
\end{tabular}




\section{Game model with LFA.}

3.1. Truncated subgame. In this paper, we apply the approach first described in [10] to our game model. Assuming that at each stage $k$, players have full information about the motion equations and payoff functions within $\bar{T}$ stages, where $\bar{T}$ is a fixed value, namely information horizon. At the stage $k$, information about the game is updated. At the stage $k+1$ players have full information about the game structure on the interval $k+1+\bar{T}$. Each blue oval represents information that is used by the players at the beginning of each $\bar{T}$ interval (Figure 1).

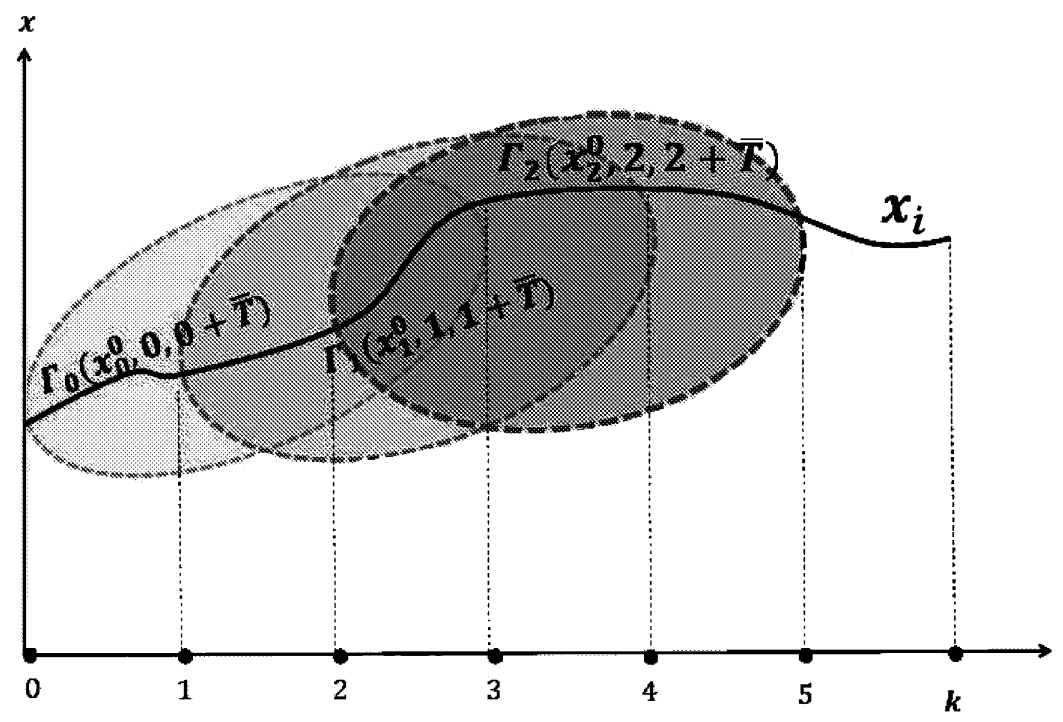

Figure 1. Behavior of player $i$ in the game with truncated information can be modeled using truncated subgames $\Gamma_{k}\left(x_{k}^{0}, k, k+\bar{T}\right), k=\overline{0, N-\bar{T}}$

Definition 3.1. Let $k=\overline{0, N-\bar{T}}$. A truncated subgame $\Gamma_{k}\left(x_{k}^{0}, k, k+\bar{T}\right)$ is defined on the interval $[k, k+\bar{T}]$. Motion equation and payoff function on the interval $[k, k+\bar{T}]$ coincide with that of initial game on the same interval. Motion equation and initial condition of truncated subgame have the form

$$
\begin{gathered}
x_{i}^{k+l}=h\left(\frac{n}{n-1} \rho_{i} u_{i}^{k+l-1} \sqrt{1-x_{i}^{k+l-1}}-\frac{1}{n-1} \sum_{j \in I} \rho_{j} u_{j}^{k+l-1} \sqrt{1-x_{j}^{k+l-1}}\right)- \\
-(h \delta-1) x_{i}^{k+l-1}+h \delta \frac{1}{n} \\
x_{i}^{0}=z_{i}^{0} .
\end{gathered}
$$

(Denote $x_{i}^{k, l}=x_{i}^{k+l}, u_{i}^{k, l}=u_{i}^{k+l}, l=\overline{0, \bar{T}}$ for the truncated subgame $\Gamma_{k}\left(x_{k}^{0}, k, k+\bar{T}\right)$.)

The payoff function of firm $i$ in truncated subgame $\Gamma_{k}\left(x_{k}^{0}, k, k+\bar{T}\right)$ has the form

$$
\bar{K}_{i}^{k}\left(x_{i}^{k, 0} ; u_{1}, \ldots, u_{n}\right)=\sum_{j=0}^{\bar{T}}\left[m_{i} x_{i}^{k, j}-\left(u_{i}^{k, j}\right)^{2}\right] .
$$

3.2. Cooperative game model. Suppose that all players or firms decided to cooperate on advertising and use some allocation rule for the joint cooperative income. In 
order to model their behaviour and feasible parameters of agreement it is necessary to do following things [19]:

1) define the cooperative strategies, i. e. strategies that maximize joint payoff of players. These strategies and corresponding cooperative trajectory will be denoted by $u^{*}=\left(u_{1}^{*}, \ldots, u_{n}^{*}\right)$ and $x^{*}(t)$ respectively;

2) define the allocation rule for maximum joint payoff along the cooperative trajectory $x^{*}(t)$ and corresponding strategies $u^{*}=\left(u_{1}^{*}, \ldots, u_{n}^{*}\right)$. Namely, define the cooperative solution, as a subset of imputation set.

We focus on considering $k$ th truncated subgame $\Gamma_{k}\left(x_{k}^{0}, k, k+\bar{T}\right)$. Suppose that all firms decide to cooperate in each truncated subgame, denote by $\Gamma_{k}^{c}\left(x_{k}^{0}, k, k+\bar{T}\right)$ truncated cooperative subgame on the interval $[k, k+\bar{T}]$ with the initial condition $x_{k}^{0}$. Then the corresponding optimization problem to be solved has the form

$$
\sum_{i \in I} \bar{K}_{i}^{k}\left(x_{i}^{k, 0} ; u_{1}, \ldots, u_{n}\right)=\sum_{i \in I} \sum_{j=0}^{\bar{T}}\left[m_{i} x_{i}^{k, j}-\left(u_{i}^{k, j}\right)^{2}\right] \rightarrow \max _{u_{1}, \ldots, u_{n} \geqslant 0}
$$

subject to $(3)$.

This is a discrete time optimization problem. We use the dynamic programming method described in [20] to solve it. Suppose that the Bellman function for each truncated subgame $\Gamma_{k}^{c}\left(x_{k}^{0}, k, k+\bar{T}\right)$ has the form

$$
W^{k}\left(l, x_{k}^{l}\right)=\max _{u_{i}(k) \geqslant 0, i \in I}\left\{\sum_{i \in I} \sum_{j=l}^{\bar{T}}\left[m_{i} x_{i}^{k, j}-\left(u_{i}^{k, j}\right)^{2}\right]\right\},
$$

where $u_{i}(k)=\left\{u_{i}^{k, l}, \ldots, u_{i}^{k, \bar{T}}\right\}$ and $l=\overline{0, \bar{T}}$.

Hamilton-Jacobi-Bellman equations for the function (5) have the form

$$
\begin{aligned}
W^{k}\left(l, x_{k}^{l}\right)=\max _{u_{i}(k) \geqslant 0, i \in I}\left\{\sum_{i \in I}\left[m_{i} x_{i}^{k, l}-\left(u_{i}^{k, l}\right)^{2}\right]+W^{k}\left(l+1, x_{k}^{l+1}\right)\right\}, \\
W^{k}\left(\bar{T}+1, x_{k}^{\bar{T}+1}\right)=0 .
\end{aligned}
$$

Assume that the maximum in (6) is achieved under control $u_{i}^{*}(k)$, then $u_{i}^{*}(k)$ is optimal in the control problem defined by $(3),(4)$.

Denote the solution of (3) with optimal strategies $u^{*}$ involved by the cooperative trajectory, $x_{k}^{*, l}=\left(x_{1}^{*, k, l}, \ldots, x_{n}^{*, k, l}\right), \quad l=\overline{0, \bar{T}}$.

Proposition 3.1. Optimal cooperative strategies of players for each truncated subgame have the form

$$
u_{i}^{*, k, l}=\bar{G}_{i}^{k, l+1} Z_{i} \sqrt{1-x_{i}^{k, l}} \quad \forall i \in I,
$$

where

$$
G_{i}^{k, l+1}=n C_{i}^{k, l+1}-\sum_{j \in I} C_{j}^{k, l+1}, \quad \bar{G}_{i}^{k, l+1}=\max \left\{0, G_{i}^{k, l+1}\right\}, \quad Z_{i}=\frac{h \rho_{i}}{2(n-1)},
$$

and $C_{i}^{k, l}, i \in\{1, \ldots, n\}, k=\overline{0, N-\bar{T}}, l=[0, \bar{T}]$, satisfy the relations

$$
C_{i}^{k, l}=m_{i}-\left(\bar{G}_{i}^{k, l+1} Z_{i}\right)^{2}-C_{i}^{k, l+1}(\delta h-1)
$$

with initial conditions $C_{i}^{k, \bar{T}+1}=0$. 
P r o o f. Suppose that the Bellman function has the following form:

$$
W^{k}\left(l, x_{k}^{l}\right)=\sum_{i \in I}\left[C_{i}^{k, l} x_{i}^{k, l}+D_{i}^{k, l}\right]
$$

then by substituting (7) into (6) we receive:

$$
\begin{gathered}
W^{k}\left(l, x_{k}^{l}\right)=\max _{u_{1}^{k, l}, \ldots, u_{n}^{k, l} \geqslant 0}\left\{\sum_{i \in I}\left[m_{i} x_{i}^{k, l}-\left(u_{i}^{k, l}\right)^{2}\right]+W^{k}\left(l+1, x_{k}^{l+1}\right)\right\} \Rightarrow \\
\Rightarrow \sum_{i \in I}\left[C_{i}^{k, l} x_{i}^{k, l}+D_{i}^{k, l}\right]=\max _{u_{1}^{k}, \ldots, u_{n}^{k} \geqslant 0}\left\{\sum_{i \in I}\left[m_{i} x_{i}^{k, l}-\left(u_{i}^{k, l}\right)^{2}\right]+\sum_{i \in I}\left[C_{i}^{k, l+1} x_{i}^{k, l+1}+D_{i}^{k, l+1}\right]\right\}, \\
W^{k}\left(\bar{T}+1, x_{k}^{\bar{T}+1}\right)=0 .
\end{gathered}
$$

Substitute the right hand side of (3) for (8). Performing the indicated maximization in (8) yields

$$
\begin{aligned}
u_{i}^{*, k, l} & =\max \left\{0,\left(n C_{i}^{k, l+1}-\sum_{j \in I} C_{j}^{k, l+1}\right) \frac{h \rho_{i} \sqrt{1-x_{i}^{k, l}}}{2(n-1)}\right\}= \\
& =\frac{h \rho_{i} \sqrt{1-x_{i}^{k, l}}}{2(n-1)} \max \left\{0, n C_{i}^{k, l+1}-\sum_{j \in I} C_{j}^{k, l+1}\right\}
\end{aligned}
$$

for $i \in I, l=\overline{0, \bar{T}}$ and $k=\overline{0, N-\bar{T}}$. Substituting it into the equation for (8) with $x_{i}^{k+l}$ defined by the right hand side of $(3), C_{i}^{k, l}$ and $D_{i}^{k, l}$ are defined as

$$
\begin{aligned}
C_{i}^{k, l} & =m_{i}-\left(\bar{G}_{i}^{k, l+1} Z_{i}\right)^{2}-C_{i}^{k, l+1}(\delta h-1), \\
D_{i}^{k, l} & =\left(\bar{G}_{i}^{k, l+1} Z_{i}\right)^{2}+\frac{C_{i}^{k, l+1} \delta h}{n}+D_{i}^{k, l+1} .
\end{aligned}
$$

The proposition is proved.

Proposition 3.2. If for a given $k$ and $l$ values $C_{i}^{k, l+1}$ are not all equal, then there exist $s \in I$ such that $G_{s}^{k, l+1}<0$ and $u_{s}^{*, k, l}=0$.

P r o o f. Suppose that $C_{s}^{k, l+1}=\min _{i \in I} C_{i}^{k, l+1}$. According to the Proposition 3.1

$$
G_{s}^{k, l+1}=n C_{s}^{k, l+1}-\sum_{j \in I} C_{j}^{k, l+1}=\sum_{j \in I}\left[C_{s}^{k, l+1}-C_{j}^{k, l+1}\right] .
$$

In the last sum all the components are non-positive and all $C_{j}^{k, l+1}$ are not equal, then at least one value $C_{s}^{k, l+1}-C_{j}^{k, l+1}$ is negative. It follows that $G_{s}^{k, l+1}<0$ and as a result $u_{s}^{*, k, l}=0$. The proposition is proved.

Proposition 3.3. If all $C_{i}^{k, l+1}$ are equal, then $u_{i}^{*, k, l}=0$ for all $i \in I$.

P r o o f. According to the definition of $G_{i}^{k, l+1}$ if $C_{i}^{k, l+1}$ are equal, then it follows that $G_{i}^{k, l+1}=u_{i}^{*, k, l}=0$ for all $i \in I$. The proposition is proved.

Further we derive the non-negativity conditions of market shares $x^{*}$ corresponding to the cooperative strategies $u^{*}$. 
Proposition 3.4. Value of $x_{i}^{* k, l}$ is non-negative, if and only if the following conditions are satisfied:

$$
\begin{gathered}
\sum_{j \in I \backslash P}\left(1-x_{j}^{*, k, l}\right)\left(h \delta-1-2 G_{j}^{k, l+1} Z_{j}^{2}\right)-(h \delta-1)\left(1+p-\sum_{j \in P \backslash\{i\}} x_{j}^{*, k, l}\right)+\frac{h \delta}{n} \geqslant 0, i \in P, \\
\left(2(n-1) G_{i}^{k, l+1} Z_{i}^{2}+1-h \delta\right) \sum_{j \in I \backslash\{i\}} x_{j}^{*, k, l}- \\
-\sum_{j \in I \backslash(P \cup\{i\})} 2 G_{j}^{k, l+1} Z_{j}^{2}\left(1-x_{j}^{*, k, l}\right)+1+\frac{h \delta(1-n)}{n} \geqslant 0, i \in I \backslash P,
\end{gathered}
$$

where $P=\left\{i: u_{i}^{* k, l}=0\right\} ; I \backslash P=\left\{i: u_{i}^{* k, l}>0\right\} ; p=|P|$.

$\mathrm{P}$ r o o f. Let $u_{i}^{*, k, l}=0, i \in P$. By substituting optimal cooperative strategies $u_{i}^{*, k, l}, i \in I$, in (3) the corresponding cooperative trajectory is obtained:

$$
x_{i}^{*, k, l+1}=-\sum_{j \in I \backslash P} 2 G_{j}^{k, l+1} Z_{j}^{2}\left(1-x_{j}^{*, k, l}\right)-(h \delta-1) x_{i}^{*, k, l}+\frac{h \delta}{n}, \quad i \in P .
$$

By replacing $x_{i}^{*, k, l}$ with $\left(1-\sum_{j \in I \backslash\{i\}} x_{j}^{*, k, l}\right)$ in equality (11) we obtain:

$$
\begin{gathered}
x_{i}^{*, k, l+1}= \\
=-\sum_{j \in I \backslash P} 2 G_{j}^{k, l+1} Z_{j}^{2}\left(1-x_{j}^{*, k, l}\right)-(h \delta-1)\left(1+p-\sum_{j \in I \backslash P}\left(1-x_{j}^{*, k, l}\right)-\sum_{j \in P \backslash\{i\}} x_{j}^{*, k, l}\right)+\frac{h \delta}{n}= \\
=-\sum_{j \in I \backslash P}\left(1-x_{j}^{*, k, l}\right)\left(2 G_{j}^{k, l+1} Z_{j}^{2}-(h \delta-1)\right)-(h \delta-1)\left(1+p-\sum_{j \in P \backslash\{i\}} x_{j}^{*, k, l}\right)+\frac{h \delta}{n} \geqslant 0 .
\end{gathered}
$$

For $i \in I \backslash P: u_{i}^{*, k, l}>0$ :

$$
\begin{gathered}
x_{i}^{*, k, l+1}=2 n G_{i}^{k, l+1} Z_{i}^{2}\left(1-x_{i}^{*, k, l}\right)-\sum_{j \in I \backslash P} 2 G_{j}^{k, l+1} Z_{j}^{2}\left(1-x_{j}^{*, k, l}\right)-(h \delta-1) x_{i}^{*, k, l}+\frac{h \delta}{n}= \\
=2 n G_{i}^{k, l+1} Z_{i}^{2}\left(1-x_{i}^{*, k, l}\right)-2 G_{i}^{k, l+1} Z_{i}^{2}\left(1-x_{i}^{*, k, l}\right)-\sum_{j \in I \backslash(P \cup\{i\})} 2 G_{j}^{k, l+1} Z_{j}^{2}\left(1-x_{j}^{*, k, l}\right)- \\
-(h \delta-1) x_{i}^{*, k, l}+\frac{h \delta}{n}=\left(2(n-1) G_{i}^{k, l+1} Z_{i}^{2}+1-h \delta\right)\left(1-x_{i}^{*, k, l}\right)- \\
-\sum_{j \in I \backslash(P \cup\{i\})} 2 G_{j}^{k, l+1} Z_{j}^{2}\left(1-x_{j}^{*, k, l}\right)+1+\frac{h \delta(1-n)}{n}= \\
\left.=\sum_{j \in I \backslash(P \cup\{i\})} 2(n-1) G_{i}^{k, l+1} Z_{i}^{2}+1-h \delta\right) \sum_{j \in I \backslash\{i\}} x_{j}^{*, k, l}- \\
-\sum_{j}^{k, l+1} Z_{j}^{2}\left(1-x_{j}^{*, k, l}\right)+1+\frac{h \delta(1-n)}{n} \geqslant 0 .
\end{gathered}
$$


From the formulas for $x_{i}^{* k, l}$ derived above it follows that the conditions (9), (10) are equvalent and that $x_{i}^{* k, l} \geqslant 0$.

The proposition is proved.

If conditions of Proposition 3.2 are satisfied, then according to $\sum_{i \in I} x_{i}^{k, l}=1$ for $k=\overline{0, N-\bar{T}}$ and $l=\overline{0, \bar{T}}$ the value of $x_{i}^{*, k, l+1}$ won't exceed 1 .

It's worth mentioning that the advertising effort rate of each firm is equal to zero, when all the firms are symmetric, because of the whole market acting as a monopoly, when all symmetric firms decide to cooperate, once consumers want to buy goods they have to buy it from one of firms, even if firms do not spend on advertising.

Proposition 3.5. If all firms are identical: $m_{i}=m, \rho_{i}=\rho$ for $i \in I$, then the optimal cooperative strategies of players are

$$
u_{i}^{*, k, l}=0, \forall i \in I, k=\overline{0, N-\bar{T}}, l=\overline{0, \bar{T}} .
$$

P r o o f. Optimal cooperative strategies can be obtained in the form

$$
u_{i}^{*, k, l}=\max \left\{0,\left(n C_{i}^{k, l+1}-\sum_{j \in I} C_{j}^{k, l+1}\right) \frac{h \rho \sqrt{1-x_{i}^{k, l}}}{2(n-1)}\right\}
$$

for $i \in I, k=\overline{0, N-\bar{T}}$ and $l=\overline{0, \bar{T}}$. Here we will examine only the second term in (12) because if $u_{i}^{*, k, l}=0$, then the result is trivial.

Consider the case when all firms are identical: $m_{i}=m, \rho_{i}=\rho$ for $i \in I$, then related parameters in Proposition 3.1 can be rewritten as follows:

$$
C_{i}^{k, l}=m-\left(\bar{G}_{i}^{k, l+1} Z\right)^{2}-C_{i}^{k, l+1}(\delta h-1),
$$

where $Z=\frac{h \rho}{2(n-1)}$ and $\bar{G}_{i}^{k, l+1}=\max \left\{0, n C_{i}^{k, l+1}-\sum_{j \in I} C_{j}^{k, l+1}\right\}$ with initial conditions $C_{i}^{k, \bar{T}+1}=0$. It shows that the value of $C_{i}^{k, l}$ is equal for all $i \in I, k=\overline{0, N-\bar{T}}$ and $l=\overline{0, \bar{T}}$, which means the optimal cooperative strategies equal to 0 for any stage when all firms are identical.

The proposition is proved.

Definition 3.2. Resulting cooperative strategies $\left\{\hat{u}_{i}^{*, j}\right\}_{j=0}^{N}, \forall i \in I$, are a combination of optimal cooperative strategies $u_{i}^{*, k, l}$ for each truncated cooperative subgame $\Gamma_{k}^{c}\left(x_{k}^{*}, k, k+\bar{T}\right)$ defined on the successive intervals $[k, k+\bar{T}]$ :

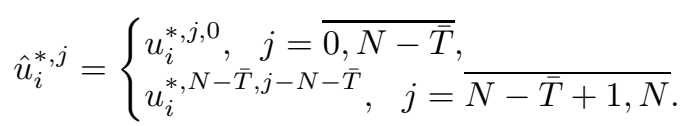

Definition 3.3. Resulting cooperative trajectory $\left\{\bar{x}_{j}^{*}\right\}_{j=0}^{N}$, is a combination of cooperative trajectories $x_{k}^{*}$ for each truncated cooperative subgame $\Gamma_{k}^{c}\left(x_{k}^{*}, k, k+\bar{T}\right)$ defined on the successive intervals $[k, k+\bar{T}]$ :

$$
\left\{\bar{x}_{j}^{*}\right\}_{j=0}^{N}=\left\{\begin{array}{l}
x_{j}^{*, 0}, \quad j=\overline{0, N-\bar{T}} \\
x_{N-\bar{T}}^{*, j-(N-\bar{T})}, \quad j=\overline{N-\bar{T}+1, N} .
\end{array}\right.
$$

In this paper we focus on allocation problem of the joint payoff among the players (see (13)). Resulting imputation with LFA differs from the imputations in the initial game, 
which is a result of difference of resulting characteristic function and characteristic function in the initial game.

3.3. Characteristic function. A characteristic function of coalition is an essential concept in the theory of cooperative games. In this paper it is defined in $[20,21]$ as a total payoff of players from coalition $S \subseteq I$ in Nash equilibrium in the game with the following set of players: coalition $S$ (acting as one player) and players from the set $N \backslash S$ (acting as individuals). For each coalition $S \subseteq I$ define the values of characteristic function for each truncated subgame as it was done in [10]:

$$
V^{k}\left(S ; x_{k}^{*, 0}\right)= \begin{cases}\sum_{i \in I} \bar{K}_{i}^{k}\left(x_{k}^{*, 0}, u^{*}\right), & S=I, \\ \tilde{V}_{k}\left(S, x_{k}^{*, 0}\right), & S \subset I, \\ 0, & S=\emptyset .\end{cases}
$$

In form (14) $\tilde{V}_{k}\left(S, x_{k}^{*, 0}\right)$ is defined as a total payoff of players from coalition $S$ in Nash equilibrium $u^{N E}=\left(\bar{u}_{1}, \ldots, \bar{u}_{n}\right)$ in the game with the following set of players: coalition $S$ (acting as one player) and players from the set $|I \backslash S|$, i. e. in the game with $|I \backslash S|+1$ players.

Suppose that the characteristic function for coalition $S$ in truncated subgame $\Gamma_{k}^{c}\left(x_{k}^{0}, k, k+\bar{T}\right)$ has the form defined above, then in order to find values of it we need to use the system of Bellman equations for Nash equilibrium between players: $S \subseteq I$ (acting as one) and players $i \in I \backslash S$. Introduce the following Bellman functions, where $V^{k}\left(S, x_{k}^{0}\right)$ will be used as a characteristic function in the truncated subgame $\Gamma_{k}\left(x_{k}^{0}, k, k+\bar{T}\right)$ :

$$
\begin{aligned}
& V^{k}\left(S, x_{k}^{0}\right)=\sum_{i \in I} \bar{C}_{i}^{k, 0} x_{i}^{k, 0}+E^{k, 0}, \quad S \subseteq I, \\
& V^{k}\left(\{i\}, x_{k}^{0}\right)=\sum_{i \in I} A_{i}^{k, 0} x_{i}^{k, 0}+B(i)^{k, 0}, \quad i \in I \backslash S,
\end{aligned}
$$

then the corresponding system of Bellman equations has the form

$$
\begin{gathered}
V^{k}\left(S, x_{k}^{0}\right)=\max _{u_{i}^{k}, \forall i \in S}\left\{\sum_{i \in S}\left[m_{i} x_{i}^{k, 0}-\left(u_{i}^{k}\right)^{2}\right]+V^{k}\left(S, x_{k}^{1}\right)\right\}, \quad S \subseteq I, \\
V^{k}\left(\{i\}, x_{k}^{0}\right)=\max _{u_{i}^{k}}\left\{m_{i} x_{i}^{k, 0}-\left(u_{i}^{k}\right)^{2}+V^{k}\left(\{i\}, x_{k}^{1}\right)\right\}, \quad \forall i \in I \backslash S, \\
V^{k}\left(S ; x_{k}^{\bar{T}+1}\right)=0, \quad V^{k}\left(\{i\} ; x_{k}^{\bar{T}+1}\right)=0 .
\end{gathered}
$$

In order to allocate cooperative payoff along the resulting cooperative trajectory, we define the resulting characteristic function in the way it was done in [10].

Definition 3.4. Resulting characteristic function of coalition $S \subseteq I$ in the game model with dynamic updating has the following form:

$$
\hat{V}\left(S ; \bar{x}_{\gamma}^{*}, N-\gamma\right)=\left\{\begin{array}{l}
\sum_{j=\gamma}^{N-1-\bar{T}}\left[V^{j}\left(S ; x_{j}^{*, 0}\right)-V^{j}\left(S ; x_{j}^{*, 1}\right)\right]+V^{N-\bar{T}}\left(S ; x_{N-\bar{T}}^{*, 0}\right), \gamma=\overline{0, N-\bar{T}}, \\
V^{N-\bar{T}}\left(S ; x_{N-\bar{T}}^{*, \gamma-N+\bar{T}}\right), \gamma=\overline{N-\bar{T}+1, N} .
\end{array}\right.
$$

4. Resulting cooperative solution. Using the resulting characteristic function (15) it is possible to define allocation rule for the cooperative payoff since it shows the value for each possible coalition. Imputation $\xi^{k}\left(x_{k}^{*}\right)$ for each truncated cooperative subgame $\Gamma_{k}^{c}\left(x_{k}^{*}, k, k+\bar{T}\right)$ is defined as an arbitrary vector, which satisfies the conditions: 
individual rationality: $\xi_{i}^{k}\left(x_{i}^{*, k, 0}, k, k+\bar{T}\right) \geqslant V^{k}\left(\{i\} ; x_{k}^{*, 0}\right), i \in I$, group rationality: $\quad \sum_{i \in I} \xi_{i}^{k}\left(x_{i}^{*, k, 0}, k, k+\bar{T}\right)=V^{k}\left(N ; x_{k}^{*, 0}\right)$.

In this paper, we choose Shapley value as a cooperative solution:

$$
S h_{i}^{k}\left(x_{k}^{*, 0}\right)=\sum_{S \subseteq I, i \in S} \frac{(|I|-|S|) !(|S|-1) !}{|I| !} \cdot\left[V^{k}\left(S ; x_{k}^{*, 0}\right)-V^{k}\left(S \backslash i ; x_{k}^{*, 0}\right)\right] .
$$

According to LFA procedure, the imputation received by the players $i \in I$ can be calculated according the following formula [14]:

$$
\hat{\xi}_{i}\left(\bar{x}_{\gamma}^{*}, N-\gamma\right)=\left\{\begin{array}{l}
\sum_{j=\gamma}^{N-1-\bar{T}}\left[\xi_{i}^{j}\left(x_{i}^{*, j, 0}, j, j+\bar{T}\right)-\xi_{i}^{j}\left(x_{i}^{*, j, 1}, j, j+\bar{T}\right)\right]+ \\
+\xi_{i}^{N-\bar{T}}\left(x_{i}^{* N-\bar{T}, 0}, N-\bar{T}, N\right), \gamma=\overline{0, N-\bar{T}}, \\
\xi_{i}^{N-\bar{T}}\left(x_{i}^{*, N-\bar{T}, \gamma-N+\bar{T}}, N-\bar{T}, N\right), \quad \gamma=\overline{N-\bar{T}+1, N},
\end{array}\right.
$$

which is called the resulting imputation. It can be proved that the resulting imputation (16) obtained by choosing from each truncated subgame Shapley value is equal to the Shapley value calculated using the resulting characteristic function (15).

Proposition 4.1. Suppose that in every truncated subgame $\Gamma_{k}^{c}\left(x_{k}^{*}, k, k+\bar{T}\right)$ :

$$
\xi_{i}^{k}\left(x_{i}^{*, k, 0}, k, k+\bar{T}\right)=S h_{i}^{k}\left(x_{k}^{*, 0}\right),
$$

where $k=\overline{0, N-\bar{T}}$, then the resulting imputation $\hat{\xi}_{i}\left(\bar{x}_{\gamma}^{*}, N-\gamma\right)$ coincides with Shapley value $\hat{S h} h_{i}\left(\bar{x}_{\gamma}^{*}, N-\gamma\right)$ :

$$
\hat{\xi}_{i}\left(\bar{x}_{\gamma}^{*}, N-\gamma\right)=\hat{S h} h_{i}\left(\bar{x}_{\gamma}^{*}, N-\gamma\right), \quad \gamma \in[0, N],
$$

calculated using the resulting characteristic function $\hat{V}\left(S, \bar{x}_{\gamma}^{*}, N-\gamma\right)$.

P r o o f. Denote function

$$
y(\gamma)=\left\{\begin{array}{l}
N-\bar{T}+1, \gamma=\overline{1, N-\bar{T}} \\
\gamma, \gamma=\overline{N-\bar{T}+1, N}
\end{array}\right.
$$

According to (16), the resulting imputation is calculated using the Shapley value $S h^{k}\left(x_{k}^{*}, k, k+\bar{T}\right)$ in each truncated subgame:

$$
\begin{aligned}
& \hat{\xi}\left(x_{\gamma}^{*}, N-\gamma\right)=\sum_{j=\gamma}^{N-\bar{T}}\left[S h^{j}\left(x_{j, 0}^{*}, j, j+\bar{T}\right)-S h^{j}\left(x_{j, 1}^{*}, j+1, j+\bar{T}\right)\right]+ \\
& +\sum_{j=y(\gamma)}^{N}\left[S h^{N-\bar{T}}\left(x_{N-\bar{T}, j-N+\bar{T}}^{*}, j, N\right)-S h^{N-\bar{T}}\left(x_{N-\bar{T}, j+1-N+\bar{T}}^{*}, j+1, N\right)\right]= \\
& =\sum_{S \subset I, i \in S} \frac{(|I|-|S|) !(|S|-1) !}{|I| !}\left\{\sum _ { j = k } ^ { N - \overline { T } } \left[\left(V\left(S ; x_{j, 0}^{*}, j, j+\bar{T}\right)-\right.\right.\right. \\
& \left.\left.-V\left(S ; x_{j, 1}^{*}, j+1, j+\bar{T}\right)\right)-\left(V\left(S \backslash i ; x_{j, 0}^{*}, j, j+\bar{T}\right)-V\left(S \backslash i ; x_{j, 1}^{*}, j+1, j+\bar{T}\right)\right)\right]+ \\
& +\sum_{j=y(\gamma)}^{N}\left[\left(V\left(S ; x_{N-\bar{T}, j-N+\bar{T}}^{*}, j, N\right)-V\left(S ; x_{N-\bar{T}, j+1-N+\bar{T}}^{*}, j+1, N\right)\right)-\right. \\
& \text { - } \left.\left.\left(V\left(S \backslash i ; x_{N-\bar{T}, j-N+\bar{T}}^{*}, j, N\right)-V\left(S \backslash i ; x_{N-\bar{T}, j+1-N+\bar{T}}^{*}, j+1, N\right)\right)\right]\right\},
\end{aligned}
$$


where $\hat{S h}\left(x^{*}, N-\gamma\right)$ is Shapley value, calculated using the resulting characteristic function $\hat{V}\left(S, \bar{x}_{\gamma}^{*}, N-\gamma\right)$

$$
\begin{aligned}
& \hat{S h}\left(x_{\gamma}^{*}, N-\gamma\right)= \\
& =\sum_{S \subset I, i \in S} \frac{(|I|-|S|) !(|S|-1) !}{|I| !}\left(\hat{V}\left(S ; \bar{x}_{\gamma}^{*}, N-\gamma\right)-\hat{V}\left(S \backslash i ; \bar{x}_{\gamma}^{*}, N-\gamma\right)\right)= \\
& =\sum_{S \subset I, i \in S} \frac{(|I|-|S|) !(|S|-1) !}{|I| !}\left\{\sum _ { j = \gamma } ^ { N - \overline { T } } \left[\left(V\left(S ; x_{j, 0}^{*}, j, j+\bar{T}\right)-\right.\right.\right. \\
& \left.\left.-V\left(S ; x_{j, 1}^{*}, j+1, j+\bar{T}\right)\right)-\left(V\left(S \backslash i ; x_{j, 0}^{*}, j, j+\bar{T}\right)-V\left(S \backslash i ; x_{j, 1}^{*}, j+1, j+\bar{T}\right)\right)\right]+ \\
& +\sum_{j=y(\gamma)}^{N}\left[\left(V\left(S ; x_{N-\bar{T}, j-N+\bar{T}}^{*}, j, N\right)-V\left(S ; x_{N-\bar{T}, j+1-N+\bar{T}}^{*}, j+1, N\right)\right)-\right. \\
& \left.\left.-\left(V\left(S \backslash i ; x_{N-\bar{T}, j-N+\bar{T}}^{*}, j, N\right)-V\left(S \backslash i ; x_{N-\bar{T}, j+1-N+\bar{T}}^{*}, j+1, N\right)\right)\right]\right\},
\end{aligned}
$$

comparing (17) and (18), the proposition is proved.

5. Simulation example. Consider oligopoly advertising dynamic game model with $n=3$ firms defined on the interval $N=8$ and information horizon $\bar{T}=2$. Let the parameters of each firm be $\rho=[0.4,0.5,0.3], h=0.4, \delta=0.09, m=[0.6,1,1.2]$ and initial conditions be $z^{0}=[0.3,0.5,0.2]$.

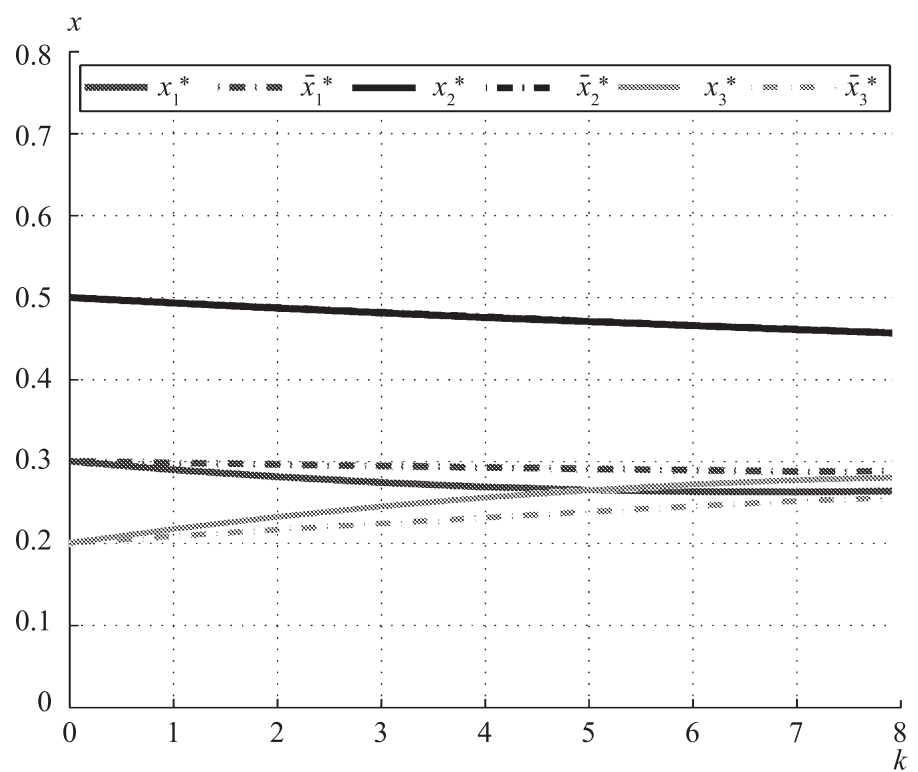

Figure 2. Cooperative trajectory in the initial game (solid line) and resulting cooperative trajectory (dashed line) in game model with dynamic updating

In Figure 2 comparison of resulting cooperative trajectory $\bar{x}^{*}$ and cooperative trajectory in the initial game is presented. Here the lines for the first player in the game model with dynamic updating and in the initial game model coincide. Also, in Figure 3 
comparison of resulting cooperative strategies $\hat{u}^{*}$ and optimal cooperative strategies in the initial game model is presented. For the first player both cooperative strategies are equal zero in Figure 3.

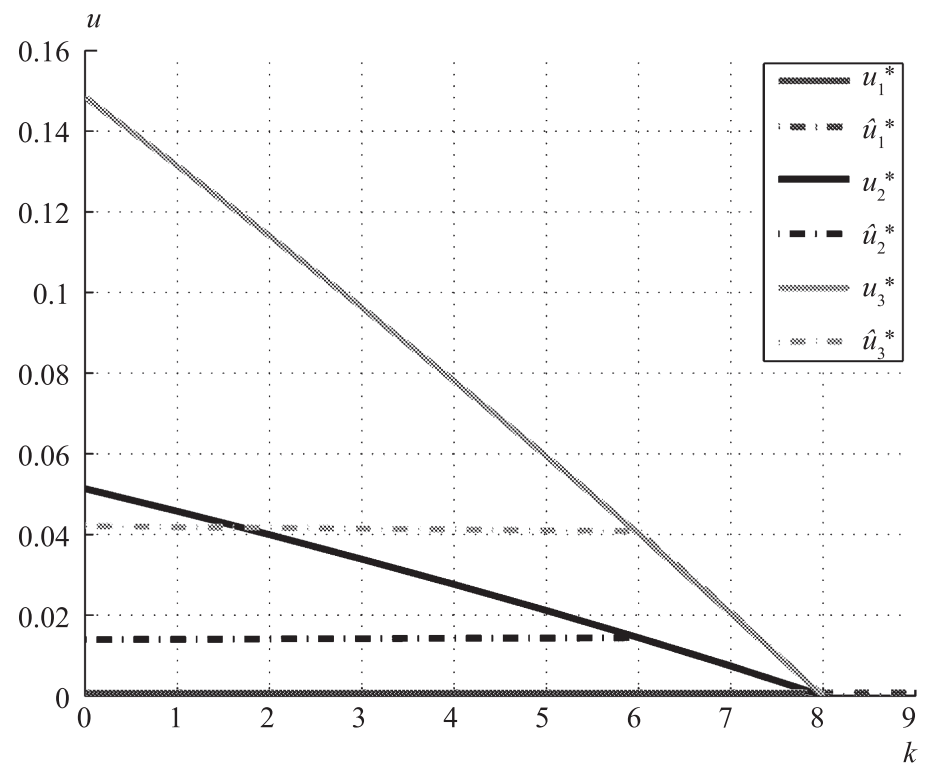

Figure 3. Optimal cooperative strategies in the cooperative case of initial game (solid line) and optimal cooperative strategies in the cooperative game model with dynamic updating (dashed line)

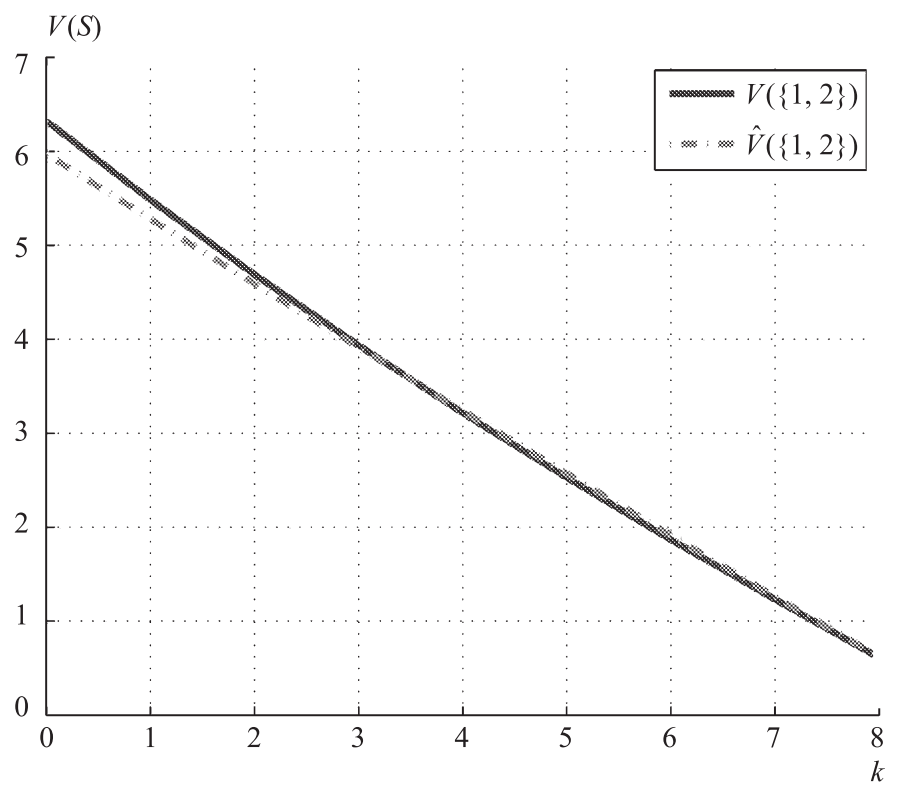

Figure 4. Characteristic function in the initial game model (solid line) and resulting characteristic function (dashed line) in game model with dynamic updating 
Using $\left\{\bar{x}_{l}^{*}\right\}_{l=0}^{N}$ formulas (14) and (15) we calculate the resulting characteristic function. In Figure 4 difference between the resulting characteristic function and characteristic function in the initial game for $S=\{1,2\}$ is presented. Using resulting characteristic function, we determine the resulting Shapley value using the formula (). In Figure 5 difference between the resulting Shapley value and Shapley value in the initial game is presented. As we can see from above, resulting Shapley value of game with LFA changes

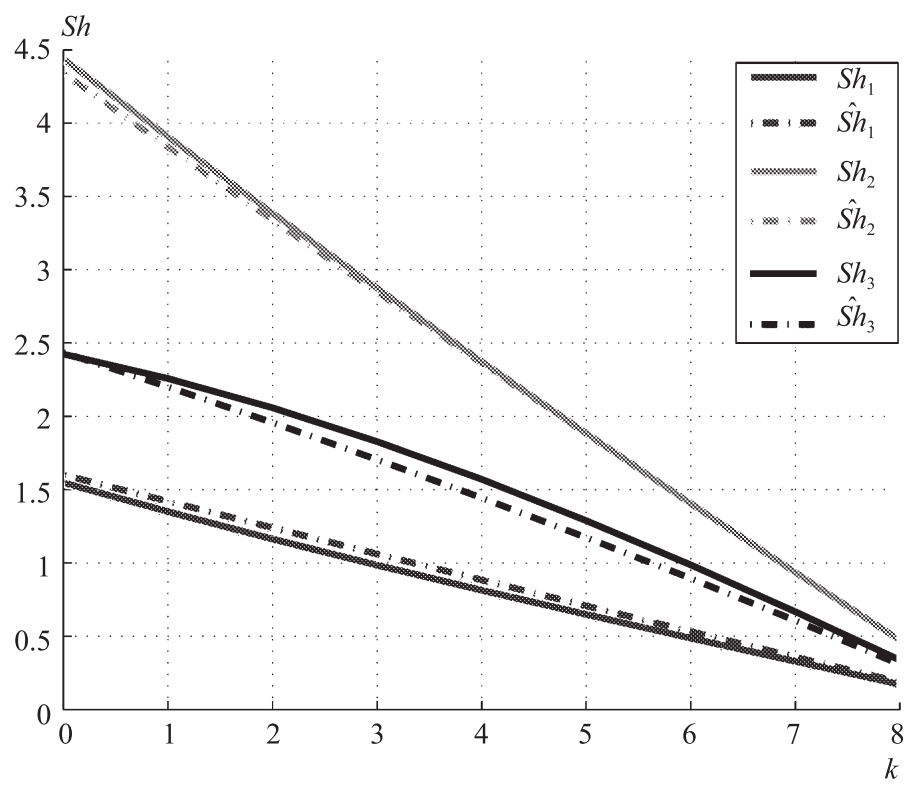

Figure 5. Shapley value in the initial game (solid line) and resulting Shapley value (dashed line) in game model with dynamic updating

more steadily over stages rather than the Shapley value of initial game. It can be seen that the competition among the companies is more fierce in the initial game rather than it in the game with LFA, considering market shares in Figure 2 and advertising expenditure in Figure 3. Shapley value of each company is barely changes on the last stage, which means that the profit of each company does not change much, as it is shown in Figure 5.

6. Conclusion. In this paper, cooperative dynamic oligopoly game model of advertising with dynamic updating has been studied and related results were presented. In future work, we are looking forward to study dynamic game with LFA, where the information horizon is random, also trying to construct an analytic formula for optimal strategies with LFA for each truncated subgame by one shot optimization. This would lead to the new results in this field.

The authors thank reviewers for their help with the paper and especially for the suggestion of adding Propositions 3.2 and 3.3.

\section{References}

1. Erickson G. M. Dynamic models of advertising competition. 2 ed. Norwell, Kluwer, Academic Publ., 2004, 122 p. 
2. Sorger G. Competitive dynamic advertising: A modification of the Case game. Journal of Economic Dynamics and Control, 1989, vol. 13, no. 1, pp. 55-80. $159 \mathrm{p}$.

3. Jorgensen S., Zaccour G. Differential games in marketing. Boston, Kluwer, Academic Publ., 2004,

4. Prasad A., Sethi S. P. Competitive advertising under uncertainty: A stochastic differential game approach. Journal of Optimization Theory and Applications, 2004, vol. 123, no. 1, pp. 163-185.

5. Prasad A., Sethi S. P., Naik P. A. Optimal control of an oligopoly model of advertising. Proceedings of the 13th IFAC Symposium on Information Control Problems in Manufacturing, INCOM 2009. Moscow, 2009, vol. 42, no. 4, pp. 91-96.

6. Naik P. A., Prasad A., Sethi S. P. Building brand awareness in dynamic oligopoly markets. Management Science, 2008, vol. 54, no. 1, pp. 129-138.

7. Yeung D. W. K., Petrosian O. L. Infinite horizon dynamic games: A new approach via information updating. International Game Theory Review, 2017, vol. 19, no. 4, pp. 1-26.

8. Gromova E. V., Petrosian O. L. Control of information horizon for cooperative differential game of pollution control. 2016 Intern. conference Stability and Oscillations of Nonlinear Control Systems, 2016, pp. 1-4.

9. Petrosian O. L., Gromova E. V. Cooperative differential games with dynamic updating. IFACPapersOnLine, 2018, vol. 51, no. 32, pp. 413-417.

10. Petrosian O. L. Looking Forward Approach in cooperative differential games. International Game Theory Review, 2016, vol. 18, no. 2, pp. 1-14.

11. Petrosian O. L., Nastych M. A., Volf D. A. Differential game of oil market with moving informational horizon and non-transferable utility. 2017 Constructive Nonsmooth Analysis and Related Topics, 2017, pp. 1-4.

12. Petrosian O. L., Nastych M. A., Volf D. A. Non-cooperative differential game model of oil market with Looking Forward Approach. Frontiers of Dynamic Games, Game Theory and Management, Saint Petersburg, 2017. Eds by L. A. Petrosyan, V. V. Mazalov, N. Zenkevich. Birkhauser, Basel, Springer Publ., 2018, pp. 189-202.

13. Petrosian O. L., Barabanov A. Looking Forward Approach in cooperative differential games with uncertain stochastic dynamics. Journal of Optimization Theory and Applications, 2017, vol. 172, no. 2, pp. 328-347.

14. Petrosian O. L. Looking Forward Approach in cooperative differential games. Saint Petersburg, Saint Petersburg State University Publ., 2017. Available at: http://disser.spbu.ru/files/disser2/disser/ Wvm58zpgrB.pdf (accessed: 02.04.2019).

15. Novikov D. A., Smirnov I. M., Shokhin T. E. Control mechanisms for dynamic active systems. Moscow, IPU RAN Publ., 2002, 124 p.

16. Goodwin G. C., Seron M. M., De Dona J. A. Constrained control and estimation - an optimization perspective. London, Springer Publ., 2005, 411 p.

17. Kwon W. H., Han S. H. Receding horizon control: Model predictive control for state models. New York, Springer Publ., 2005, 380 p.

18. Wang C., Ong C. J., Sim M. Convergence properties of constrained linear system under MPC control law using affine disturbance feedback. Automatica, 2009, vol. 45, no. 1, pp. 1715-1720.

19. Yeung D. W. K., Petrosyan L. A. Subgame-consistent economic optimization. New York, Springer Publ., 2012, 395 p.

20. Bellman R. Dynamic programming. Princeton, Princeton University Press, 1957, 365 p.

21. Chander P., Tulkens H. A core-theoretic solution for the design of cooperative agreements on trans-frontier pollution. Public goods, environmental externalities and fiscal competition. New York, Springer Publ., 2006, pp. 176-193.

Received: March 01, 2019.

Accepted: March 15, 2019.

Author's information:

Lihong Shi - Master; shilihongru@gmail.com

Ovanes L. Petrosian - assistant; petrosian.ovanes@yandex.ru

Alina V. Boiko - Master; alina.boyko@mail.ru 


\title{
Модель игры о рекламе с динамическим обновлением информации*
}

\author{
Л. Ши, О. Л. Петросян, А. В. Бойко
}

Санкт-Петербургский государственный университет, Российская Федерация, 199034, Санкт-Петербург, Университетская наб., 7-9

Для цитирования: Shi L., Petrosian O. L., Boiko A. V. Looking forward approach for dynamic cooperative advertising game model // Вестник Санкт-Петербургского университета. Прикладная математика. Информатика. Процессы управления. 2019. Т. 15. Вып. 2. С. 221-234. https://doi.org/10.21638/11702/spbu10.2019.206 (In English)

Рассматривается динамическая модель, описывающая игру на рынке рекламы, в которой доля каждой фирмы зависит от ее собственных и рекламных политик конкурентов. Все больше и больше компаний готовы сотрудничать на рынке, чтобы в результате увеличить свои рыночную долю и прибыль. Компании сотрудничают в области рекламы, действуя как одна компания, и в соответствии с характерной функцией и некоторым кооперативным решением, представленными в данной работе, их совместная прибыль может быть перераспределена. Подход с динамическим обновлением информации применяется к исходной игре, чтобы построить модель, в которой информация о процессе обновляется с течением времени. С помощью численного моделирования проведено сравнение решения исходной игровой модели и игровой модели с динамическим обновлением.

Ключевые слова: динамичные игры, динамичные кооперативные игры, динамическая устойчивость, динамическое обновление информации.

Контактная информация:

Ши Лихун - магистр; shilihongru@gmail.com

Петросян Ованес Леонович - ассистент; petrosian.ovanes@yandex.ru

Бойко Алина Владимировна - магистр; alina.boyko@mail.ru 00081).

* Работа выполнена при финансовой поддержке Российского научного фонда (проект № 18-71- 